\title{
Updated guidelines for device-based therapy of cardiac rhythm abnormalities
}

\author{
A. Marc Gillinov, MD
}

In September 2012, a joint committee, including representatives from the American College of Cardiology Foundation, American Heart Association, and Heart Rhythm Society, released a focused update of the 2008 guidelines for device-based therapy of cardiac rhythm abnormalities. ${ }^{1}$ The writing committee included representatives from The American Association for Thoracic Surgery and the Society of Thoracic Surgeons. The update focused on the indications for cardiac resynchronization therapy (CRT) and follow-up of pacemakers and other devices. Because cardiac surgeons care for patients who require these devices, this update is relevant to our practice.

\section{CHANGING INDICATIONS FOR CRT}

The writing committee carefully reviewed a large number of new studies evaluating the effectiveness of CRT in various populations of patients with heart failure. The new indications for CRT place increased emphasis on left bundle branch block (LBBB) pattern on the electrocardiogram and a QRS duration of $150 \mathrm{~ms}$ or greater. The 4 most significant changes in recommended indications for CRT are as follows:

1. Limitation of the class I indication to patients with QRS duration of $150 \mathrm{~ms}$ or greater

2. Limitation of the class I indication to patients with a LBBB pattern

3. Expansion of the class I indication to patients in New York Heart Association class II who also have a LBBB pattern and QRS duration of $150 \mathrm{~ms}$ or greater

4. Addition of class IIb recommendation ("may be considered") for patients in New York Heart Association class I who have left ventricular ejection fraction of $30 \%$ or less, ischemic etiology of heart failure, sinus rhythm, and both LBBB pattern and QRS duration of $150 \mathrm{~ms}$ or greater

From the Department of Thoracic and Cardiovascular Surgery, Cleveland Clinic, Cleveland, Ohio.

Disclosures: Author has nothing to disclose with regard to commercial support.

Address for reprints: A. Marc Gillinov, MD, Department of Thoracic and Cardiovascular Surgery, Cleveland Clinic, Desk J4-1, 9500 Euclid Ave, Cleveland, OH 44195 (E-mail: gillinom@ccf.org).

J Thorac Cardiovasc Surg 2012;144:1285

$0022-5223 / \$ 36.00$

Copyright (C) 2012 by The American Association for Thoracic Surgery

http://dx.doi.org/10.1016/j.jtcvs.2012.10.001
The key changes relate to the presence of the LBBB pattern on the electrocardiogram and a QRS duration of $150 \mathrm{~ms}$ or more. A meta-analysis of several clinical trials, including more than 5000 patients, confirmed that CRT provides substantial benefit in those with LBBB morphology but no clinical benefit for those without LBBB morphology. ${ }^{2}$ Multiple recent analyses have also confirmed that CRT is most beneficial for those with a QRS duration of $150 \mathrm{~ms}$ or more. In contrast, a QRS duration less than $150 \mathrm{~ms}$ is a risk factor for failure to respond to CRT. No large trial has shown a benefit for CRT in those with normal QRS duration.

Selected patients who have either a modestly prolonged QRS (range, 120 to $149 \mathrm{~ms}$ ) without a LBBB pattern or QRS duration of $150 \mathrm{~ms}$ or more without a LBBB pattern received a class IIa recommendation for CRT provided that their left ventricular ejection fraction is $35 \%$ or less. Of note, CRT is not indicated for patients who have New York Heart Association class I or II symptoms and a non-LBBB pattern with a QRS duration of less than $150 \mathrm{~ms}$.

For those with ischemic cardiomyopathy, CRT is indicated more than 40 days after myocardial infarction or more than 3 months after revascularization. The updated guidelines do not support the placement of CRT at revascularization.

\section{PACEMAKER FOLLOW-UP}

The update notes the utility of remote monitoring for cardiac implantable electrical devices (pacemakers, implantable cardioverter defibrillators, CRTs, loop recorders, and implantable hemodynamic monitors). A review of recent trials suggests that most device assessments can be performed remotely, although an annual in-person visit remains standard for those patients with a pacemaker, implantable cardioverter defibrillator, or CRT.

\section{References}

1. Tracy CM, Epstein AE, Darbar D, DiMarco JP, Dunbar SB, Estes NAM, et al. 2012 ACCF/AHA/HRS focused update of the 2008 guidelines for device-based therapy of cardiac rhythm abnormalities: a report of the American College of Cardiology Foundation/American Heart Association Task Force on Practice Guidelines. J Thorac Cardiovasc Surg. 2012;144:e127-45.

2. Sipahi I, Carrigan TO, Rowland DY, Stambler BS, Fang JC. Impact of QRS duration on clinical event reduction with cardiac resynchronization therapy: meta-analysis of randomized controlled trials. Arch Intern Med. 2011;171: 1454-62. 